\title{
Near-complete resolution of Nerve Constriction in Neuralgic Amyotrophy on Magnetic Resonance Neurography
}

Robin Warner, DO ( $\square$ robin.petrizzo@gmail.com )

Hospital for Special Surgery https://orcid.org/0000-0002-0590-5090

Esther Zusstone, MD

College of Medicine, University of Cincinnati, Cincinnati, Ohio, USA.

Joseph Feinberg, MD

Hospital for Special Surgery

Ogonna Nwawka, MD

Hospital for Special Surgery

Darryl Sneag, MD

Hospital for Special Surgery

\section{Case Report}

Keywords: MR neurography, Brachial neuritis, Brachial plexitis

Posted Date: September 29th, 2020

DOl: https://doi.org/10.21203/rs.3.rs-83295/v1

License: (c) (1) This work is licensed under a Creative Commons Attribution 4.0 International License. Read Full License 


\section{Abstract}

INTRODUCTION/BACKGROUND: The diagnosis of brachial plexitis is based on history and clinical findings, supported by needle EMG and MRI. MR neurography can detect focal and multifocal inflammation within nerve.

OBJECTIVE: To determine if MR neurography allows objective data mirroring clinical improvement in brachial plexitis.

CASE REPORT: A 39-year-old man developed sudden onset pain in his left shoulder after a mild infection, which intensified over 3-4 days. Weakness followed, being unable to lift his left arm above the level of his shoulder. There were no sensory symptoms. There was a remote history of Bell's palsy, but no relevant family history. Initial examination showed weakness of the left deltoid and infraspinatus (2/4). Reflexes were present. Needle EMG/NCSs showed left C5 radiculopathy, primarily involving the anterior ramus division with severe denervation of C5-innervated muscles, then progressive reinnervation of the $\mathrm{C} 5$ muscles through axonal regeneration. A left brachial plexus MR neurography with gadolinium showed an enlarged hyperintensity in the $\mathrm{C} 5$ nerve root at the level of the interscalene triangle with a denervation pattern edema of regional muscles. The patient was treated with IVIg. Ten months after onset, strength of all muscles is normal, although there is decreased muscle bulk in his deltoid and pectoral muscles. Serial MRIs show progressively decreasing nerve root hyperintensity and size in the post foraminal nerve root. The last MRI and needle EMG/NCSs were normal, correlating with the clinical syndrome.

SUMMARY/CONCLUSION: MR neurography of the brachial plexus may be important in diagnosis and prognosis in patients with brachial plexitis.

\section{Introduction}

The signature presentation of neuralgic amyotrophy (NA), eponymously Parsonage-Turner syndrome (PTS), is sudden onset upper arm pain and sensory disturbance escalating over a few hours and improving over 2-3 weeks. Severe weakness in the distribution of one or more upper extremity nerve distributions following this pain prodrome then ensues. ${ }^{3}$

Intrinsic constrictions of extraplexal nerves have been recognized in NA patients on high-resolution magnetic resonance neurography (MRN) and ultrasound (US). ${ }^{4,5-7}$ Here, we describe an unusual intraplexal constriction of the extraforaminal $\mathrm{C} 5$ nerve root with near-complete resolution documented by MRN and coinciding with clinical and electrodiagnostic (EDX) improvement.

\section{Case Report}

A 39 year-old man developed severe pain in the left shoulder with subsequent inability to abduct the arm above shoulder level. His past medical history included Bell's palsy 7 years prior, which resolved with 
corticosteroids, but was complicated by osteonecrosis of both femoral heads requiring resurfacing hip arthroplasties.

Neurological exam 20 days after symptom onset revealed MRC grade 2/5 weakness in left shoulder abduction, 3/5 in left shoulder external rotation, 4/5 in left elbow flexion, and 5/5 in all other muscles. Sensation was decreased within the left C5 dermatome. Recruitment patterns on electromyography 20 days after symptom onset were discrete in the left deltoid, rhomboids, supraspinatus and infraspinatus, and decreased in the biceps. Left C5-6 paraspinals were normal.

Cervical spine MRI 21 days after symptom onset was normal. Same-day brachial plexus MR neurography demonstrated a $1.5 \mathrm{~cm}$ long severe constriction of the extraforaminal C5 nerve root within the interscalene triangle, $3 \mathrm{~cm}$ distal to the $\mathrm{C} 4-5$ foramen, with associated T2 signal hyperintensity of the nerve root. Denervation edema pattern of the infraspinatus, supraspinatus and deltoid muscles was noted.

The patient was diagnosed with NA and treated with intravenous immunoglobulin (IVIg) approximately one month after presentation. Improvement in strength was noted following the initial IVIg infusion ( $2 \mathrm{~g} / \mathrm{kg}$ over 5 days) and continued as a dose of $1 \mathrm{~g} / \mathrm{kg}$ every 3 weeks.

Approximately 3 months after symptom onset, physical exam demonstrated improved strength with $3 / 5$ in left shoulder abduction and external rotation. EMG showed improved motor unit recruitment in affected muscles, most notably in the supraspinatus. Brachial plexus MR neurography also 3 months after presentation demonstrated decreased severity but persistent constriction of the $\mathrm{C} 5$ nerve root. Quantitative measurement of constriction severity was not made on MRI due to spatial resolution limitations, but US at the same time measured a constriction ratio (CR) of 0.46 (CR = (diameter of proximal swollen area - diameter of constricted area) / diameter of proximal swollen area). ${ }^{8}$

At six months, there was continued strength increase and motor unit recruitment by EMG in all previously affected muscles. Repeat MR neurography demonstrated only minimal, residual constriction of the C5 nerve root and US documented a smaller CR of 0.15. Due to improvement, IVIG treatment was stopped.

EMG at 1-year showed full re-innervation of the supraspinatus, infraspinatus, biceps, and posterior deltoid head with motor unit maturation and with mild residual denervation in the middle and anterior deltoid heads.

\section{Discussion}

To our knowledge, this is the first report documenting a C5 nerve root constriction that improved clinically and radiographically following medical intervention in NA. Though the significance of nerve constrictions has not been fully elucidated, they appear specific for NA., 9-11 This case is unusual, as constrictions typically involve extraplexal nerves with the plexus proper appearing normal., 9-13 
The successful use of IVIg in NA (sometimes combined with IV steroids) although not yet studied in a randomized, prospective fashion, has been reported ${ }^{1,3-6,14,15}$ and may be more effective early in the disease course. ${ }^{3,6}$ In our patient, IVIg therapy began early with rapid resolution of symptoms, although this may can be due to IVIg or disease natural history. As we demonstrated decreased constriction following IVIg, further investigation should be performed on the role of constrictions in NA disease onset, symptomatology, and recovery. More precise measures characterizing and describing nerve enlargement and constrictions to allow meaningful and reproducible change over time is a topic of future investigation.

\section{Declarations}

The patient has provided written consent for this case study.

The authors have no conflicts of interest relevant to this manuscript.

\section{References}

1. Austin J. Sumner, M.D., Idiopathic Brachial Neuritis, Neurosurgery, Volume 65, Issue suppl_4, October 2009, Pages A150-A152, https://doi.org/10.1227/01.NEU.0000345355.59438.D1

2. Ferrante, MD. Brachial plexopathies. Continuum. Oct 2014. Vol.20, No.5 p. 1323-1342.

3. Tagliafico A, Succio G, Serafini G, Martinoli C Diagnostic performance of ultrasound in patients with suspected brachial plexus lesions in adults: a multicenter retrospective study with MRI, surgical findings and clinical follow-up as reference standard. Skeletal Radiol. 2013 Mar;42(3):371-6. Epub 2012 Jun 17.

4. Sneag, DB, Saltzman, EB, Meister, DW, Feinberg, JH, Lee, SK, and Wolfe, SW. MRI Bullseye Sign: An Indicator of Peripheral Nerve Construction in Parsonage-Turner Syndrome. July 2017. Muscle and Nerve. 56:1(99-105).

5. Arányi Z, Csillik A, Dévay K, et al. Ultrasonographic identification of nerve pathology in neuralgic amyotrophy: Enlargement, constriction, fascicular entwinement, and torsion: Ultrasonography in Neuralgic Amyotrophy. Muscle \& Nerve. 2015;52:503-511.

6. Arányi Z, Csillik A, DéVay K, et al. Ultrasonography in neuralgic amyotrophy: Sensitivity, spectrum of findings, and clinical correlations. Muscle \& Nerve. 2017;56:1054-1062.

7. Sneag DB, Rancy SK, Wolfe SW, et al. Brachial plexitis or neuritis? MRI features of lesion distribution in Parsonage-Turner syndrome. Muscle \& Nerve. 2018;58:359-366.

8. Sunagawa, T., Nakashima, Y., Shinomiya, R., Kurumadani, H., Adachi, N. and Ochi, M. (2017), Correlation between "hourglass-like fascicular constriction" and idiopathic anterior interosseous nerve palsy. Muscle Nerve, 55: 508-512. doi:10.1002/mus.25361

9. Tsairis P, Dyck PJ, Mulder DW. Natural history of brachial plexus neuropathy: report on 99 patients. Arch Neurol 1972;27:109-17. Crossref, Medline, Google Scholar 
10. Magee KR, DeJong RN. Paralytic brachial neuritis: discussion of clinical features with review of 23 cases. JAMA 1960;174:1258-62. Crossref, Medline, ISI, Google Scholar

11. Cruz-Martinez A, Barrio M, Arpa J. Neuralgic amyotrophy: variable expression in 40 patients. J Peripher Nerve Syst 2002;7:198-204. Crossref, Medline, ISI, Google Scholar

12. Johnson NE, Petraglia AL, Huang JH, Logigian EL. Rapid resolution of severe neuralgic amyotrophy after treatment with corticosteroids and intravenous immunoglobulin. Muscle \& Nerve. 2011;44:304305.

13. Nakagawa Y, Hirata H. Hourglass-Like Constriction of the Brachial Plexus in the Posterior Cord: A Case Report. Neurosurgery. 2018;82(1):E1-E5. doi:10.1093/neuros/nyx171

14. Feinberg, J.H., Nguyen, E.T., Boachie-Adjei, K., Gribbin, C., Lee, S.K., Daluiski, A. and Wolfe, S.W. (2017), The electrodiagnostic natural history of parsonage-turner syndrome. Muscle Nerve, 56: 737743. doi:10.1002/mus. 25558

15. Yongwei Pan, MD, PhD, Shufeng Wang, MD, PhD, Danfeng Zheng, PhD, Wen Tian, MD, Guanglei Tian, MD, Pak Cheong Ho, MD, Hi-shan Cheng, MD, Yanfeng Zhong, MD, Hourglass-Like Constrictions of Peripheral Nerve in the Upper Extremity: A Clinical Review and Pathological Study, Neurosurgery, Volume 75, Issue 1, July 2014, Pages 10-22, https://doi.org/10.1227/NEU.0000000000000350

\section{Figures} Supraspinatus and infraspinatus muscle
denervation

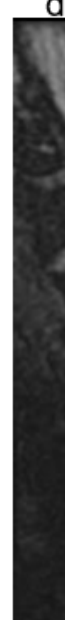

$10 / 25 / 17$
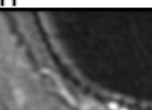

$\mathrm{Nin}^{2}$ this
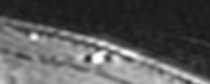

$\star x-\frac{1}{2}$ $\star$ (
C5 nerve root constriction

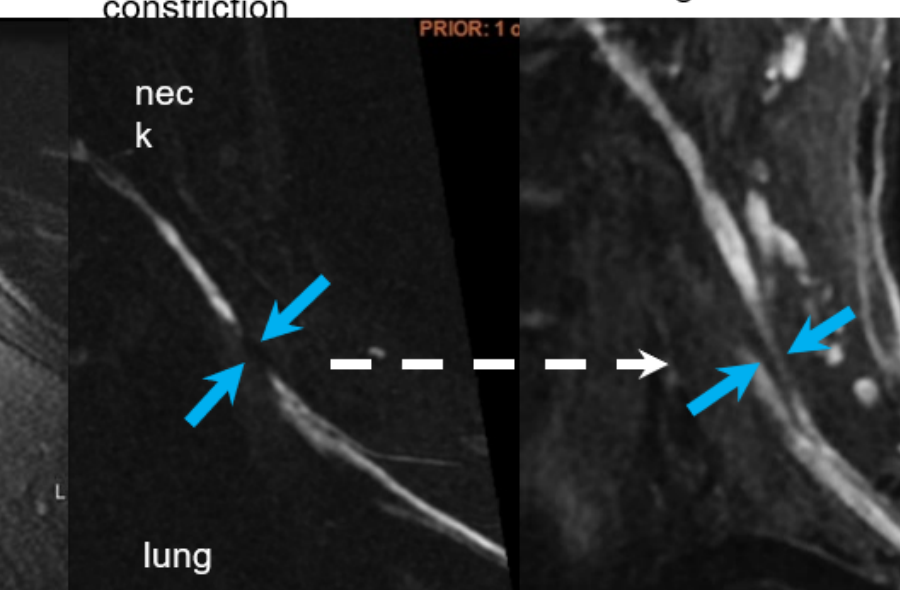

Post IVIg treatment

$10 / 25 / 17$
$4 / 10 / 18$

\section{Figure 1}

MRI Brachial Plexus 


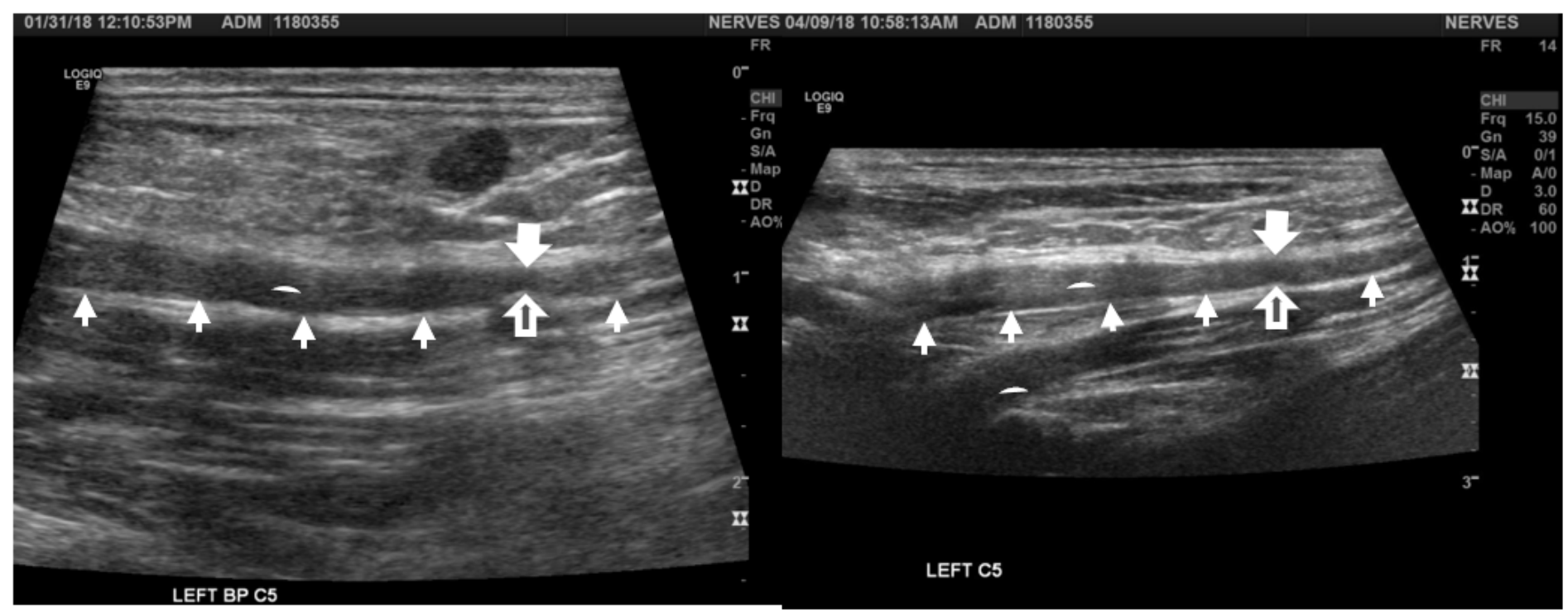

Figure 2

Ultrasound Brachial Plexus at 3 months and 6 months after symptom onset. 